\title{
Notes on the vocalizations of Great Tit (Parus major), Turkestan Tit (Parus bokharensis) and Green-backed Tit (Parus monticolus)
}

\section{Peter Boesman}

In the following we briefly analyze and compare voice of the different races of Great Tit (Parus major), Turkestan Tit (Parus bokharensis) and Green-backed Tit (Parus monticolus). We also try to quantify the extent of any vocal differences using the criteria proposed by Tobias et al. (2010), as a support for taxonomic review. We have made use of sound recordings available on-line from Xeno Canto (XC).

This taxonomic group of no less than 41 races all together, is both morphologically and vocally extremely challenging, and may well need a PhD project to truly unravel all details of vocal variation and differentiation in this complex case. There is no easy way to quantify distinguishing features, so that groups can be separated from one another. Several strategies will have to be tried out to determine whether there is any clear correlation between race and voice, and an in depth statistical analysis will surely be needed. In any case, vocal differences are subtle, and will not score very high on the 'rough scoring scale' we typically use when applying Tobias criteria. Nevertheless, we can discern some possible trends from looking at sonograms, but these are nothing more than preliminary indications:

\section{Great Tit group}

major/exelsus: Many songs have short and pure flat-pitched bell-like whistles:

Poland:
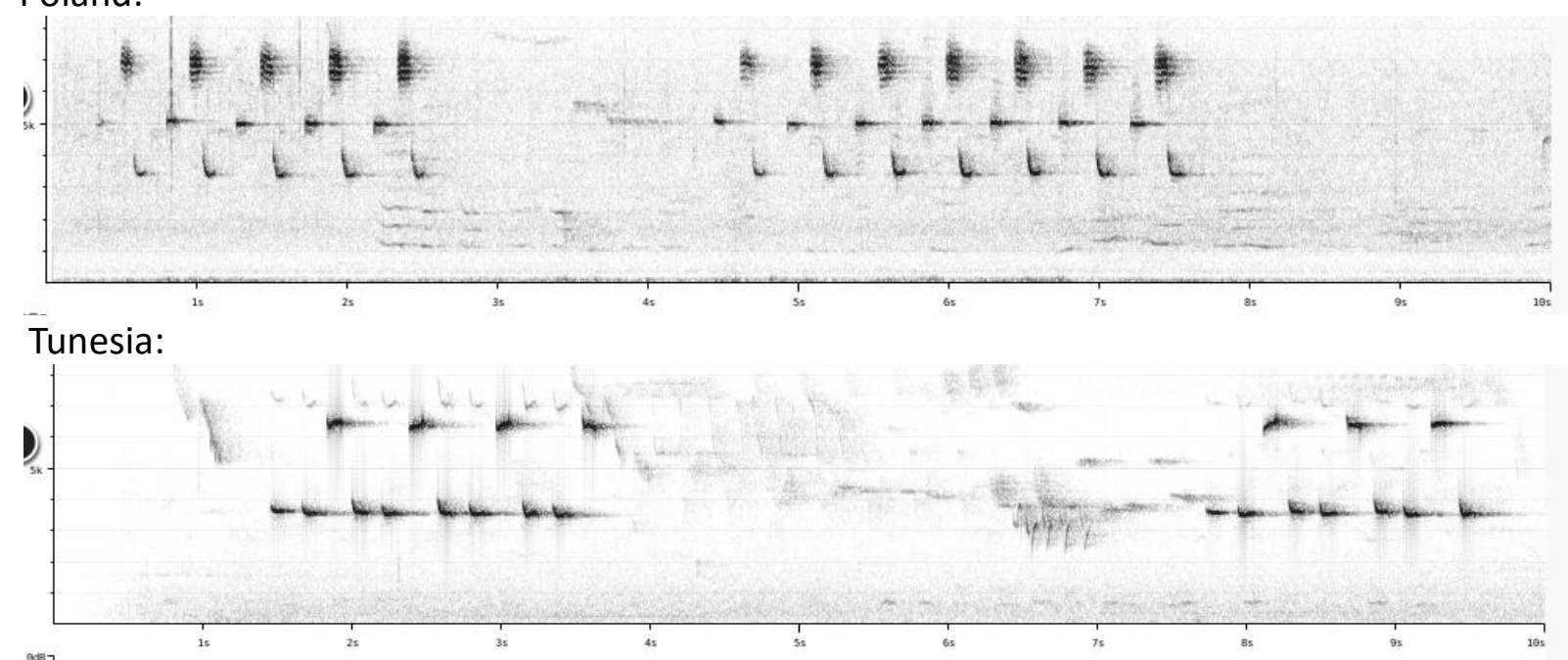

bokharensis

Similar in having mainly pure whistles, but generally lacks flat-pitched whistles:

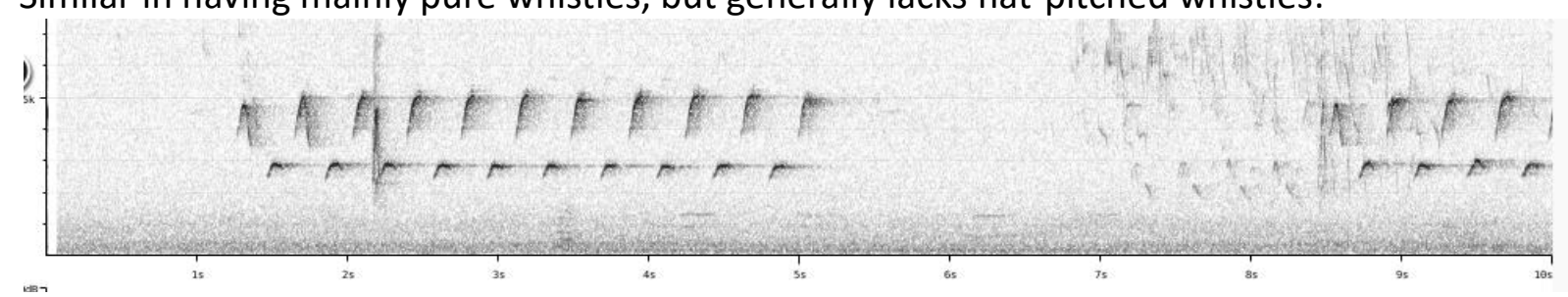


HANDBOOK OF THE

BIRDEPIJE WORLD ORNITHOLOGICAL NOTES

Japanese Tit group

All of Japan, E China, Korea, etc.: Most songs have complex notes which are not pure-sounding, never have the pure bell-like timbre of the Great Tit group. Mainly (but not exclusively) $1+1$ repeated phrases:

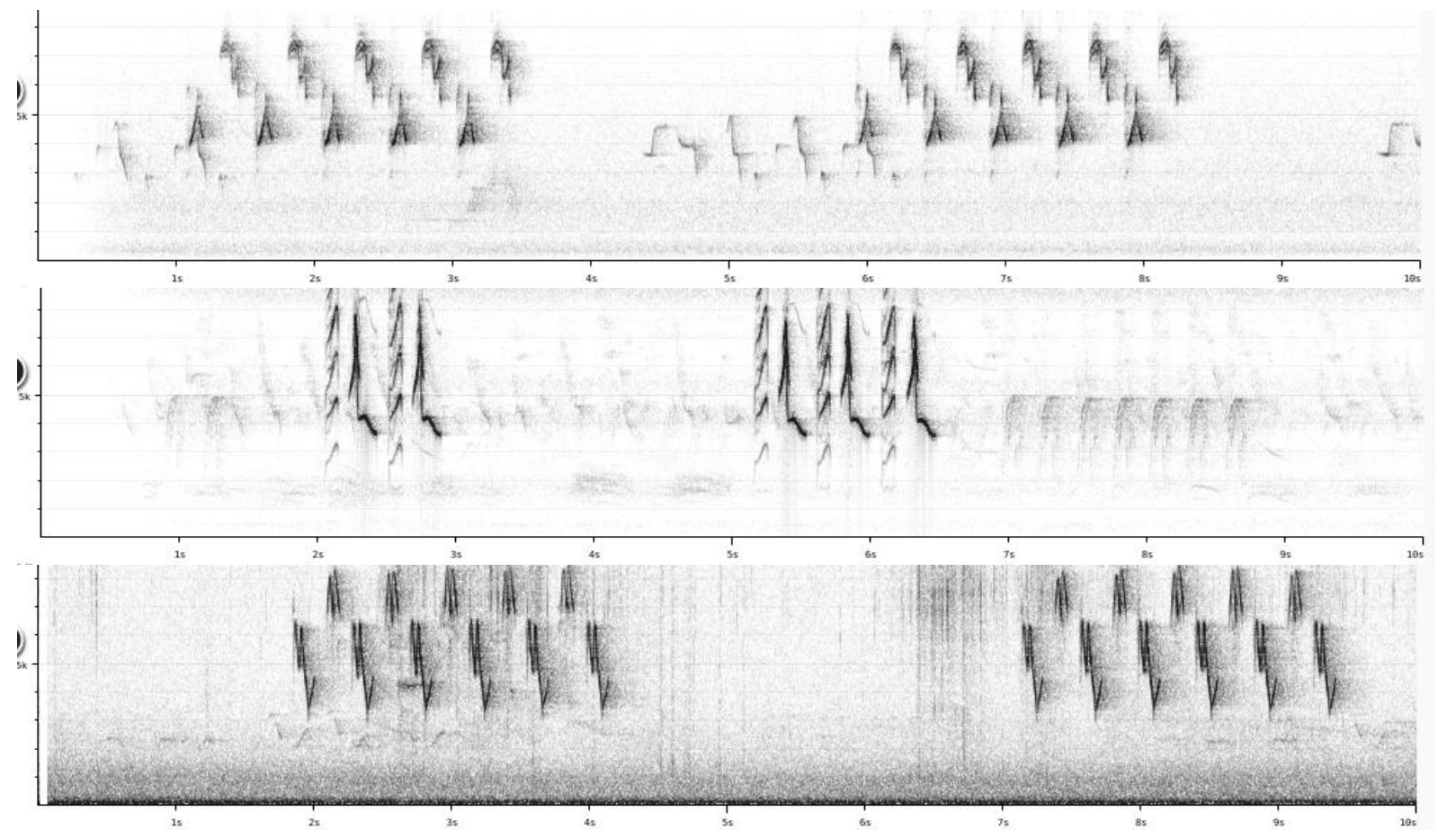

Cinereous Tit group

India and SE Asia: Seems to have often $2+1$ or $1+1+1$ phrases repeated, usually of fairly complex notes lacking the bell-like tinkling quality of the 'Great Tit group':
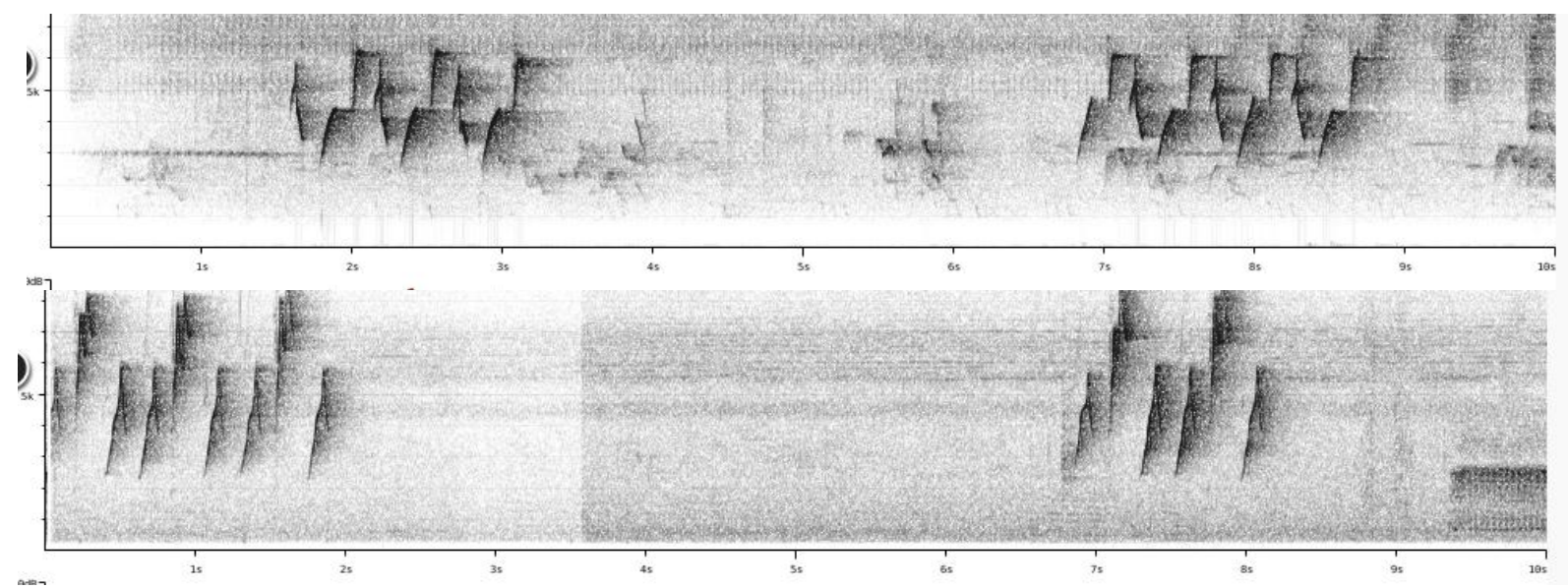

2 


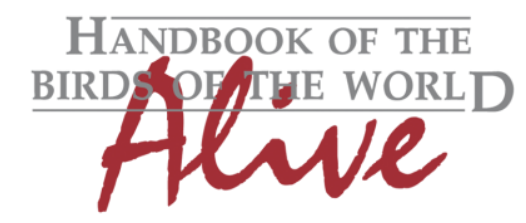

\section{ORNITHOLOGICAL NOTES}

\section{Green-backed Tit group}

Himalayas and W China: Song is often a single simple pure note repeated, something rarely seen in other groups.

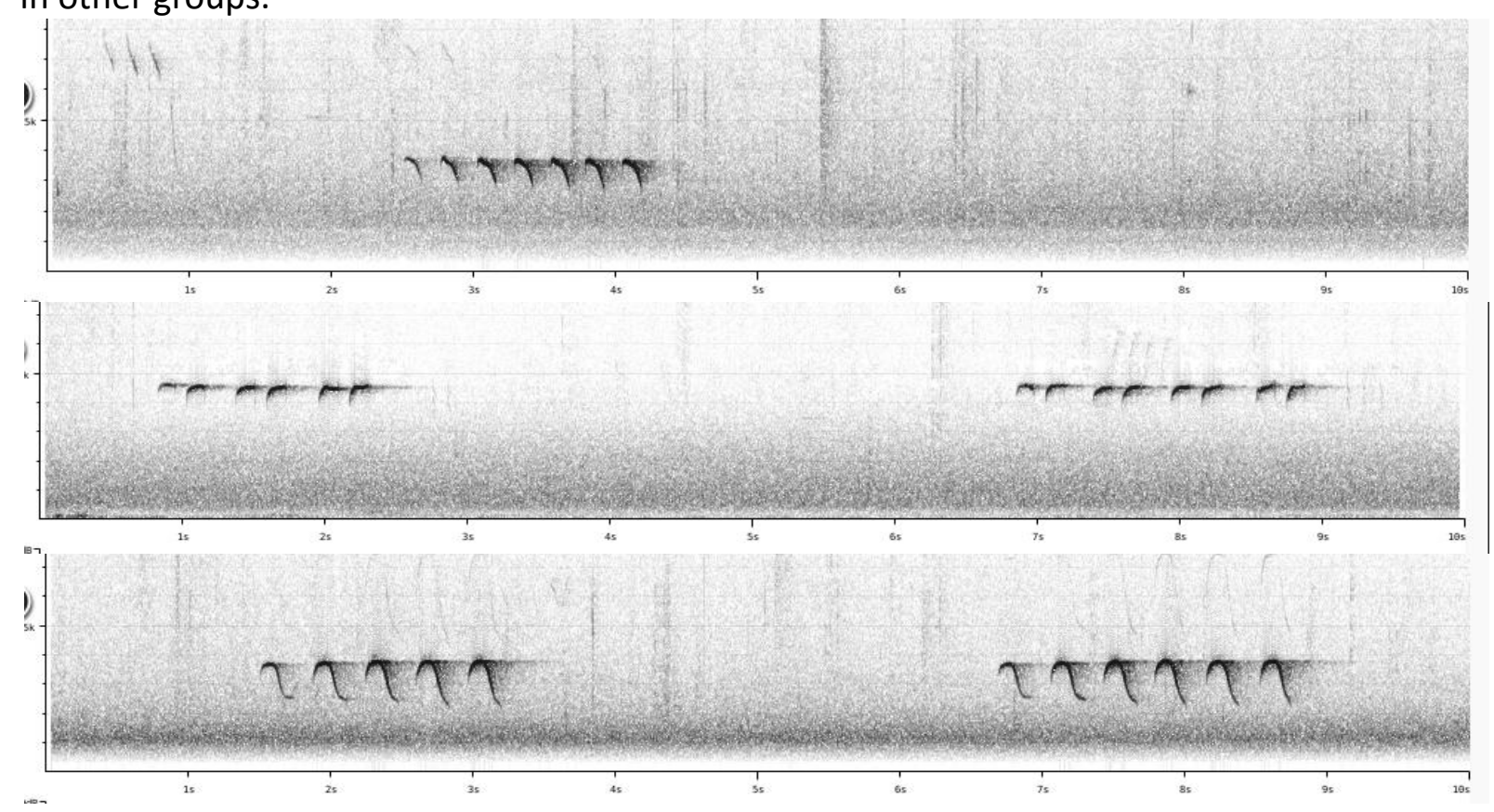

or nearly identical double notes:

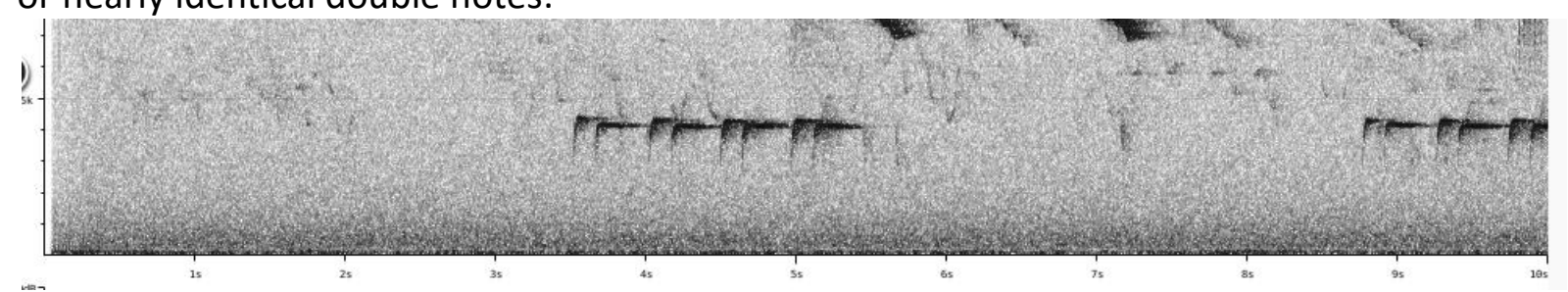

At least these four groups may well have statistically significant differences in the relative frequency of note-types and phrases delivered, with especially the 'Green-Backed Tit group' being quite distinct.

There may be further differences among certain races, but as already mentioned, discovering and quantifying these would require a major effort.

This note was finalized on 4th February 2016, using sound recordings available on-line at that moment. We would like to thank in particular the many sound recordists who placed their recordings for this species on XC.

\section{References}

Tobias, J.A., Seddon, N., Spottiswoode, C.N., Pilgrim, J.D., Fishpool, L.D.C. \& Collar, N.J. (2010). Quantitative criteria for species delimitation. Ibis 152(4): 724-746. 


\section{Recommended citation}

Boesman, P. (2016). Notes on the vocalizations of Great Tit (Parus major), Turkestan Tit (Parus bokharensis) and Green-backed Tit (Parus monticolus). HBW Alive Ornithological Note 217. In: Handbook of the Birds of the World Alive. Lynx Edicions, Barcelona. (retrieved from http://www.hbw.com/node/932175 on 6 September 2016). 